\title{
Economically optimal safety targets for riverine flood defence systems
}

\author{
E.J.C. Dupuits ${ }^{1, a}$, K.M. de Bruijn², F.L.M. Diermanse ${ }^{2}$ and M. Kok ${ }^{1}$ \\ ${ }^{1}$ Delft University of Technology, Delft, The Netherlands \\ ${ }^{2}$ Deltares, Delft, The Netherlands
}

\begin{abstract}
A breach in a flood defence will affect the downstream water levels in a riverine system, and therefore the flood risk of the system. The effect of this changed flood risk is used in an economical optimization to assess if this significantly changes the economically optimal safety targets of the flood defences in a riverine system. The impact of breaches on the flood risk and the economically optimal safety targets is modelled using simplified hydrodynamic relations and a number of conceptual case studies for small systems. Significant differences were found, but are limited to cases with a relatively high chance of breaching and/or high impact breaches. These differences seem to mostly affect the optimal heights of the flood defences, which means that including the effect of breaches can result in a different-optimal investment path.
\end{abstract}

\section{Introduction}

A river flood defence system can be defined as a series of multiple flood defences alongside a river. An example of such a series of flood defences can be found in the form of dike rings in the Dutch Rhine and Meuse river basin. If one of the flood defences breaches, the water levels downstream of the breach can change which will affect the failure probability. To determine the flood risk of the system, the effect of breaches on failure probabilities downstream need to be addressed.

Economical optimization, as it is used in The Netherlands, minimizes the total cost, which consist of the costs of building flood defences and the risk costs [1]. This can be an important tool in determining flood protection standards. The risk costs in the economical optimization are a measure of the flood risk, which means any change in the flood risk can also influence the economically optimal safety target of each flood defence.

The impact of failures on the flood risk and/or the economically optimal safety targets of a system depends on the type of system and its elements, where the definition of a system depends on the scale. A number of system types with the impact of failures on the flood risk/economical optimization can be found in literature, for example regarding hierarchal flood protection systems or multi-layer safety $[2,3]$ and coastal flood defence systems [4-6]. Specifically regarding flood risk in riverine systems, a number of approaches can be found in literature, for example in [7-12]. However, these methods focus on determining flood risks, instead of determining the economically optimal safety targets.

There are also methods to assess the economically optimal safety targets for embankment sections in the Netherlands, but these do not consider the impact of breached upstream flood defences. For example, the research in [1] uses exponentially distributed water level exceedance probabilities to model flood probabilities. A remark is made in [1] to replace the exceedance probabilities with the flood probabilities from a recent nation-wide flood risk analysis project ([13]), however this project considers flood defences along the same river as independent (i.e. does not account for the impact of a breached dike ring on the downstream dike rings).

Therefore, we will investigate the effect of including the impact of breaches on the economically optimal safety targets of flood defences in a riverine system. This will be done by starting with a conceptual case of two flood defences, which will be extended to multiple flood defences. Emphasis lies on getting an initial impression of the impact on the economically optimal safety targets for a number of conceptual case studies, which requires tractable computation times. This is achieved by using conceptually simplified hydrodynamics, risk, and economical optimization methods. Finally, a sensitivity analysis is done with respect to some key parameters and results from the economical optimization.

\section{Economically optimal with failures}

The effect of a breach can have either a positive or negative impact on other flood defences in the same system, similar to [12]. For example, a positive impact is the storage of discharge in the area behind a breach, effectively reducing the discharge for downstream flood defences (Figure 1A). An example of a negative impact is the shortcutting of a protected area (e.g. polder) which leads a higher discharge in a neighbouring river (Figure 1B).

In order to apply these impacts into economically optimal safety targets, an economical optimisation

\footnotetext{
${ }^{\mathrm{a}}$ Corresponding author: e.j.c.dupuits@tudelft.nl
} 
method is needed. In this paper, we will conceptually base the economical optimisation method on the one used in The Netherlands for the quantification of economically optimal safety targets (e.g. see [1]). The objective of this economical optimisation method is the minimisation of the total cost, which is comprised of the investment costs and the expected flood damages. However, compared to [1] we will use simpler relations, similar to earlier work in $[5,6]$ and comparable to for example [14].

First, the investment costs per flood defence are assumed to be a linear function of a fixed cost and a variable cost per meter dike height increase. The timing of the investment is fixed to a single investment at the start of the regarded time period. Time dependent processes such as economic growth, are ignored for the preliminary assessment in this study, with the purpose of obtaining a simple total cost equation. If these where not to be ignored, finding the duration and size of repeated investments would have to be part of the optimisation (e.g. $[15,16])$. Secondly, the flood risk is assumed to be the product of the annual probability of flooding times the expected annual damage given flooding; because this is an annual cost, it needs to be discounted. Thirdly, the starting height of all flood defences is assumed to be zero in the investment function. These assumptions expand the total cost relation for $n$ flood defences as follows:

$$
T C=\sum_{i=i}^{n} P_{i} \frac{D_{i}}{r}+C_{f, i}+C_{v, i} h_{i}
$$

where for flood defence $i$ the annual flooding probability is denoted by $P_{i}$, the expected damage given flooding by $D_{i}$, the fixed cost by $C_{f, i}$, the variable cost by $C_{v, i}$ and the height by $h_{i}$. Furthermore, when a damage is discounted by a discount rate $r(r>0)$ annually over an infinite time period, it converges to $D_{i} / r$ [17].

In this paper, we assume that the previously described impacts only affect the economical optimization in Equation 1 with regard to the failure probability. If the flood damages are dependent on the extent or type of flooding (e.g. see [13]), the flood damage could be impacted as well. However, in this paper, in case of a flooding a fixed number is used as an estimate for the flood damage. Furthermore, the storage of the polder areas is assumed to not be a limiting factor (i.e. the breach discharge is constant).

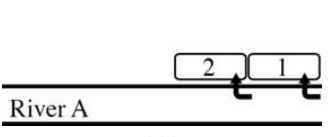

(A)

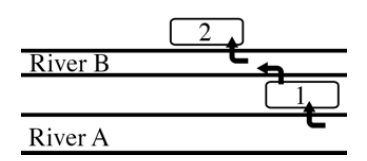

(B)
Figure 1. Positive (A) and negative (B) impact of a breach in the embankment along area 1 on the failure probability of area 2.

\section{Conceptual case}

For the conceptual case, a system with two flood defences is used to preliminary assess the effect of either a positive or a negative impact. For positive impacts, the system of Figure 1A is used, while for negative impacts Figure $1 \mathrm{~B}$ is used. As mentioned in the previous section, we assume that these impacts manifest themselves via the failure probability. Because both systems assume a breach in defence 1 in the case defence 1 fails, the consequence, or impact (either positive or negative), will be felt at defence 2 . If the probability of a breach at flood defence 1 is equalled to the failure probability of flood defence 1 , a relation for the failure probability of flood defence 2 can be found using the law of total probability as follows:

$$
P_{2}=P_{1} P_{2 \mid \text { breach }}+\left(1-P_{1}\right) P_{2 \mid \text { no_breach }}
$$

where $P_{1}$ is the probability of a breach at defence 1 , and $P_{2 \mid \text { breach }}$ is the failure probability of flood defence 2 given breached conditions at flood defence 1. Similarly, $P_{2 \mid \text { no_breach }}$ is the failure probability of flood defence 2 given no breach at flood defence 1 . In case impacts are ignored for the conceptual systems of Figure 1A and Figure 1B, Equation 2 reduces to $P_{2}=P_{2 \mid \text { no_breach }}$.

In this conceptual case, the failure probabilities will be approximated by probabilities of water level exceedance, similarly to [1]. However, in following sections this approximation will be replaced in order to represent other failure mechanisms as well. Nevertheless, for now, exponential exceedance relations are used as follows:

$$
P=\exp (-h / \beta)
$$

where for $P_{1}$ the height of flood defence $1\left(h_{1}\right)$ is used together with an exponential distribution parameter for defence $1\left(\beta_{1}\right)$. On the other hand, for both $P_{2 \mid \text { no_breach }}$ and $P_{2 \mid \text { breach }}$ the height of flood defence 2 is used, together with consecutively exponential distribution parameters $\beta_{2 \mid \text { no_breach }}$ and $\beta_{2 \mid \text { breach }}$.

With these exponential exceedance relations, the economically optimal exceedance probabilities can be found. In order to do so, Table 1 shows some hypothetical values. However, Table 1 does not show the value of the exponential distribution parameter $\beta$, because that depends on the type of impact. In case of a system with positive impact $\beta_{2 \text { no_breach }}=0.4$ and $\beta_{2 \mid \text { breach }}=0.2$. When the system with negative impact is chosen, $\beta_{2 \mid \text { no breach }}=0.2$ and $\beta_{2 \text { |breach }}=0.4$. In other words, a larger beta value leads to higher water levels for the same probability of exceedance.

\begin{tabular}{lcc}
\hline & Defence 1 & Defence 2 \\
\hline$\beta[\mathrm{m}]$ & 0.4 & See text \\
\hline$C_{f}[€]$ & $20 \cdot 10^{6}$ & $20 \cdot 10^{6}$ \\
\hline$C_{v}[€ / \mathrm{m}]$ & $10 \cdot 10^{6}$ & $10 \cdot 10^{6}$ \\
\hline$D[€]$ & $10^{5}-10^{9}$ & $10^{8}$ \\
\hline$r[-]$ & 0.04 & 0.04 \\
\hline \multicolumn{2}{r}{ Table 1. Parameter values for the conceptual systems. }
\end{tabular}

Table 1. Parameter values for the conceptual systems. 

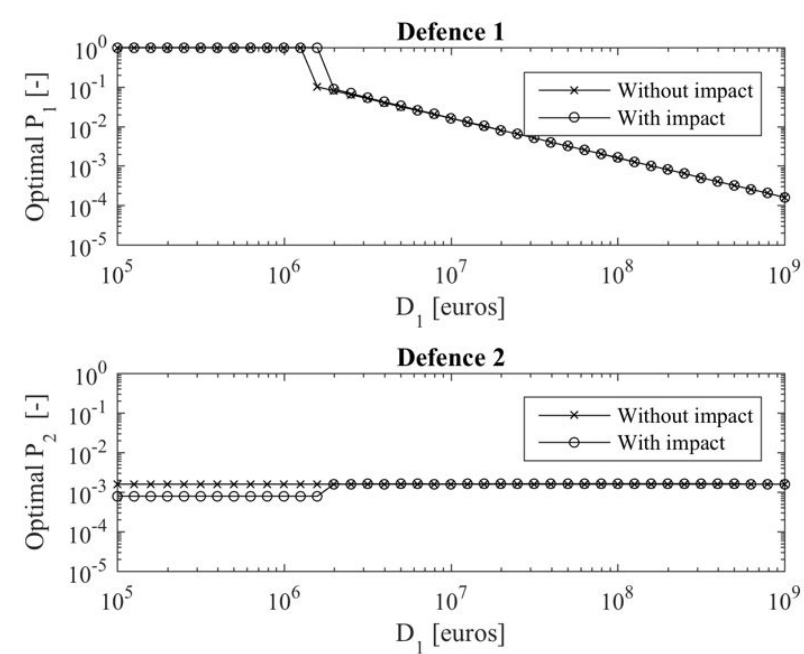

(A)

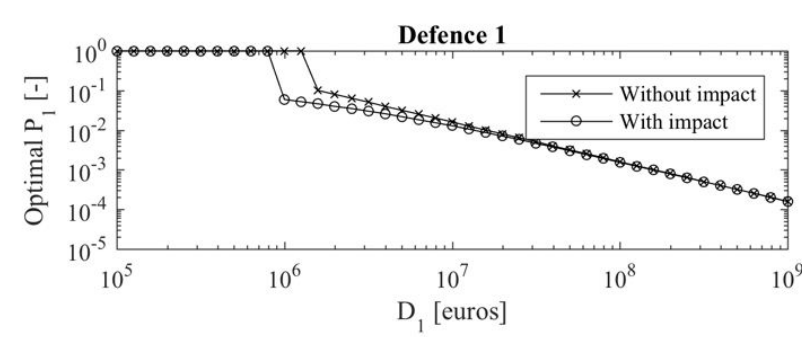

Defence 2

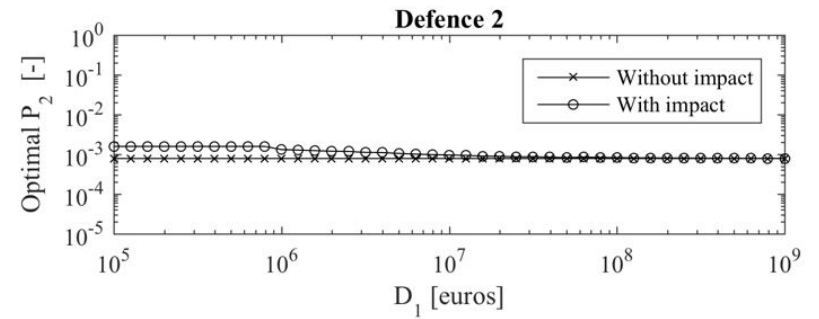

(B)

Figure 2. Optimal values for $P_{1}$ and $P_{2}$ as functions of $D_{1}$, for positive (A) and negative (B) impacts respectively. Optimal values are calculated with and without impacts.

The optimal exceedance probabilities for the conceptual systems with positive and negative impact, compared to no impact, are shown in Figure 2, as functions of $D_{l}$. These values were found by calculating the total costs for all height combinations of defence 1 and defence 2 ranging between 0 and 20 meter (step size $=0.01$ meter).

As the chosen parameter values are hypothetical, the relevancy of Figure 2 lies with the behaviour of the optimal annual exceedance probabilities as a function of the flood damage at defence 1 . The differences might be larger or smaller depending on different values for the parameters in Table 1. For a more in depth discussion of a similar conceptual system, see [5,6].

For flood defence 1, in case of a positive impact, the effect of the impact seems limited; other than requiring a slightly higher flood damage at defence 1 before building a flood defence becomes economically optimal, the exceedance probabilities with and without impact appear to be identical. However, in case of negative impact and relatively low values of the flood damage at defence 1 , building a flood defence becomes not only economically optimal sooner, but the optimal probability is smaller as well. Nevertheless, the latter effect seems to diminish once the flood damage at defence 1 becomes larger.

The plot for defence 2 in Figure 2A indicates that in case of a positive impact and relatively small flood damages at defence 1 , the optimal annual exceedance probability of defence 2 should be somewhat smaller when compared to the case where positive impacts are ignored. Intuitively, this makes sense as the load at defence 2 is smaller than when ignoring the positive impact. Nevertheless, once the optimal exceedance probability of defence 1 becomes smaller, the difference with and without impact at defence 2 difference becomes negligible. Figure 2B indicates that the opposite is true in case of negative impacts: for defence 2 , and for relatively small flood damages at defence 1 , the optimal annual exceedance probability of defence 2 should be somewhat larger when compared to the case where negative impacts are ignored. Again, intuitively, this makes sense as the load at defence 2 is larger than when ignoring the negative impact. Here too the difference between with impacts and without impact becomes negligible for smaller optimal exceedance probabilities of flood defence 1. These findings agree with the conclusions in [11].

\section{Monte Carlo flood risk simulations for economically optimal safety targets}

The conceptual case indicates that, under certain circumstances, there can be a significant effect of including the impact of breaches. However, the conceptual case has a number of shortcomings. First, the usage of exceedance probabilities instead of failure probabilities (i.e. the height of the flood defences is considered, not its resistance against other failure modes). Secondly, the conditional probabilities, as used in Equation 2, become impractical when a larger number of flood defences are used and/or with possible combinations of negative and positive impacts. Thirdly, the load reduction or load increase should preferably be modelled explicitly using breach models in the hydrodynamic analyses. In Section 4.1, these issues are addressed in two ways: the exponential exceedance relation will be replaced by a reliability function representing load and strength, and the consequences of breaches are evaluated by manipulating (peak) discharges in a Monte Carlo simulation, similar to the conceptual model as described in [12]. Furthermore, even though the Monte Carlo simulations will be relatively computationally efficient, it will be no longer feasible to run an entire height range, as was done in Section 3, for each flood defence in a system with multiple defences. A different method of approaching the system optimal configuration with impacts is described in Section 4.2.

\subsection{Flood risk method}

The failure probability of a flood defence can be represented by a reliability equation as follows:

$$
Z=R-S
$$


where $R$ is the strength of the flood defence, and $S$ is the load by the (peak) discharge of a river. The load on a flood defence will be described by a Gumbel distribution representing the (extreme) discharge distribution of the river Rhine at Lobith, as used in [18]. These discharges will be converted to equilibrium water levels (quasi uniform approach) using the Chézy formula; the chosen parameter values necessary for the calculations are listed in Table 2. The widths have been chosen in such a way that, given the discharge distribution over both rivers, the equilibrium water levels in both rivers are practically the same for any discharge.

\begin{tabular}{lcc}
\hline & River A & River B \\
\hline Discharge $(Q)\left[\mathrm{m}^{3} / \mathrm{s}\right]$ & $2 / 3 Q$ & $1 / 3 Q$ \\
\hline Width $[\mathrm{m}]$ & 1092 & 550 \\
\hline Slope $[-]$ & 0.0001 & 0.0001 \\
\hline Nikuradse $[\mathrm{m}]$ & 0.05 & 0.05 \\
\hline
\end{tabular}

Table 2. River discharge parameters.

For the strength of a flood defence a lognormal distribution is assumed, with a mean equal to the height of the flood defence, and an assumed coefficient of variation of 0.2 , similar to [6]. This lognormal distribution represents a 'critical water level' for which the flood defence fails if it is exceeded; the critical water level can be lower or higher than the actual crest height. The critical water level approach is a more integral way of describing failure probabilities, as not only the exceedance of crest level is included (overflow/overtopping), but also for example piping. Among others, the flood disaster of New Orleans due to hurricane Katrina showed that flood defences can fail at water levels below their crest height due to for example piping [19].

A Monte Carlo simulation is used to manipulate (peak) discharges as a method of describing impacts. A Monte Carlo iteration starts with sampling the critical water levels of all the flood defences, while also sampling one or more river discharges, depending on how many rivers are present in a given case. From there on, the flood defences are checked sequentially according to Equation 4 by starting at the upstream boundary. In case a flood defence fails $(Z<0)$, a breach is always assumed to occur and a fixed percentage of the discharge is subtracted from the sampled discharge for all subsequent flood defences along that same river (positive impact). On the other hand, in case of shortcutting (or negative impact), the percentage of discharge which has flown into the area behind the flood defence is added to the river that is connected to the exit point of the shortcut. This implies that the probability of shortcutting to occur, given a breach at a flood defence prone to shortcutting, is equal to one. This assumption might overestimate the impact of shortcutting, and needs to be checked when applied to a real case.

\subsection{Economical optimisation method}

In Section 3, the minimum of the total costs was determined by calculating the total cost for all combinations of defence 1 and defence 2 in a range between 0 and 20 meters, with a step size of 0.01 meter. This type of brute force calculation is no longer feasible when more than two flood defences are used, in combination with longer flood risk calculation times. For example, in case of five flood defences which each can have ten different states (or heights), the number of possible system configurations would be $10^{5}$. If each configuration would take a single second to calculate, it would take almost 28 hours to calculate all the configurations.

For this preliminary study, the number of states is reduced to five. The first state is based on the optimal height without impacts, which can be calculated using numerical integration of Equation 4. The remaining four states are based on the first state, reducing and increasing the height with 0.2 and 0.4 meter, respectively. The step size of 0.2 meter is based on similar choice in [20], where it was mentioned that smaller steps have no practical value.

These five states will not guarantee that the global minimum of the total cost is actually found. However, the findings in Section 3 suggest that the system configuration with and without impact probably do not differ greatly, which is the reason for choosing the states around the optimum without interactions. Furthermore, the goal of this study is not to find the economically optimal system configuration with impacts, but to investigate the relative difference of including impacts.

Nevertheless, for future research, more efficient calculation methods might be needed to find the optimal system configuration. This can be obtained by either reducing the flood risk calculation cost (e.g. surrogate models), and/or the number of system configurations that actually need to be calculated (e.g. a flood risk based greedy algorithm).

\section{Application}

The method described in Section 4 will be applied to a number of hypothetical systems, shown in Figure 3. These systems were chosen in order to investigate the effect of positive impacts (Figure 3A), negative impacts (Figure 3B) and both negative and positive impacts (Figure 3C).

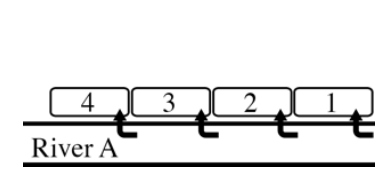

(A)

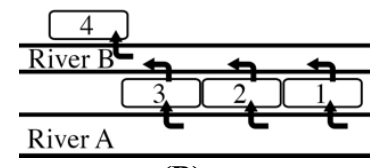

(B)

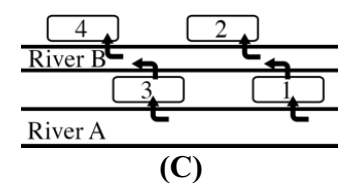

Figure 3. Three types of systems with four defences: positive impact (A), negative impact (B), and both (C). 


\subsection{Input}

Three systems, shown in Figure 3, will be optimised with and without impacts. In case impacts are included, it is assumed for all systems that if a breach occurs, a fixed percentage of the river discharge flows from the river into the polder area previously protected by the flood defence. Initially, this discharge reduction will be set at ten percent, and will be increased in Section 6. In follow up research this discharge reduction will have to be motivated by for example hydrodynamic simulations. The impact of discharge reductions on the water level, using reductions of ten and twenty percent and the parameters of Table 2, is shown in Figure 4.

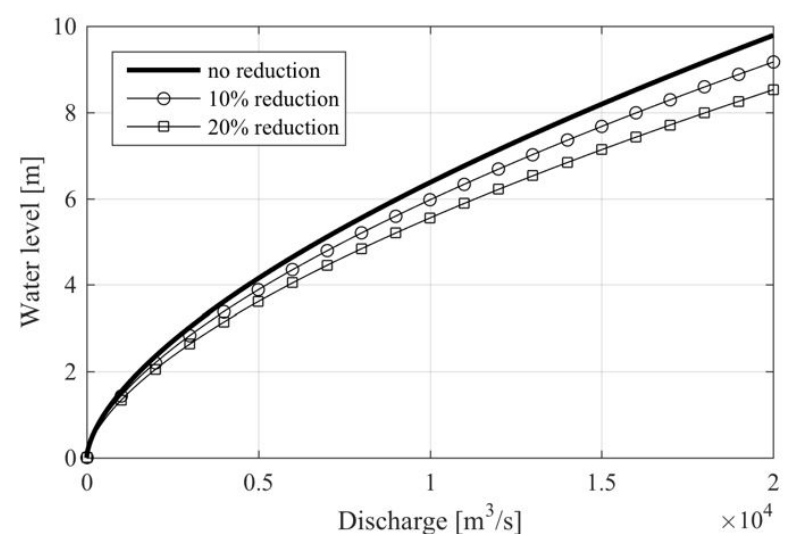

Figure 4. Water level as a function of the discharge, plotted for no reduction, $10 \%$ reduction and $20 \%$ reduction.

For the sake of the example, the systems in Figure 3B and Figure $3 \mathrm{C}$ can only shortcut in one direction: from river $\mathrm{A}$ to river $\mathrm{B}$. Furthermore, the flood defences that are prone to shortcutting are not threatened by river B. Both these simplifications can be justified for example when River B lies significantly lower than River A.

The effect of including these impacts can be shown by looking at the total number of breaches. This is done for the system in Figure 3A, and the total number of breaches are plotted in Figure 5, using a Monte Carlo run with $10^{7}$ samples with all four defence heights set to eight meter.

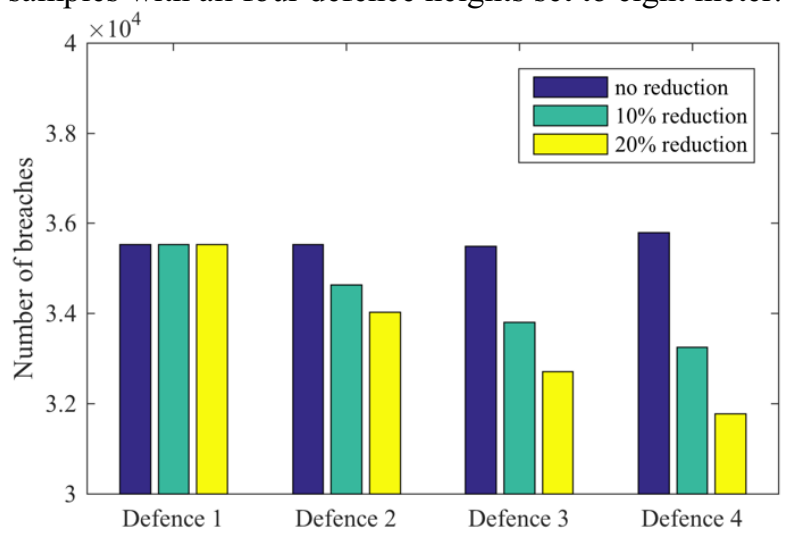

Figure 5. Number of breaches runs per defence for the system in Figure $3 \mathrm{~A}$ with $10^{7}$ samples, using no impact and positive impact (10\% and $20 \%$ discharge reduction).
Figure 5 shows that the number of breaches are approximately constant without impacts, but decreases for the downstream flood defences; the decrease is greater when a larger discharge reduction is used. Another way of looking at this is by looking at the distribution of the number of breaches per Monte Carlo run, which is shown in Figure 6. Figure 6 shows the decrease of the number of breaches can primarily be attributed to a decrease in the number of situations with more than one breach. If the damage for each defence is assumed to be equal, the same can also be displayed in a flood loss (FS) curve, as shown in Figure 7.

Regarding the investment costs and the discount rate, values are used similar to the conceptual system in Section 3. They are regarded as constant for all three system configurations, and are listed in .Table 3.

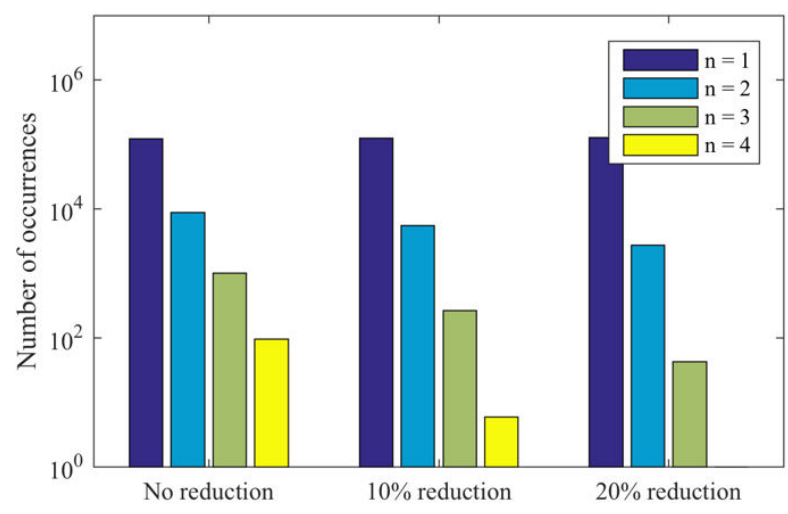

Figure 6. Distribution of the number of breaches $(n)$ for the system in Figure 3A with $10^{7}$ samples, using no impact and positive impact (10\% and $20 \%$ discharge reduction).

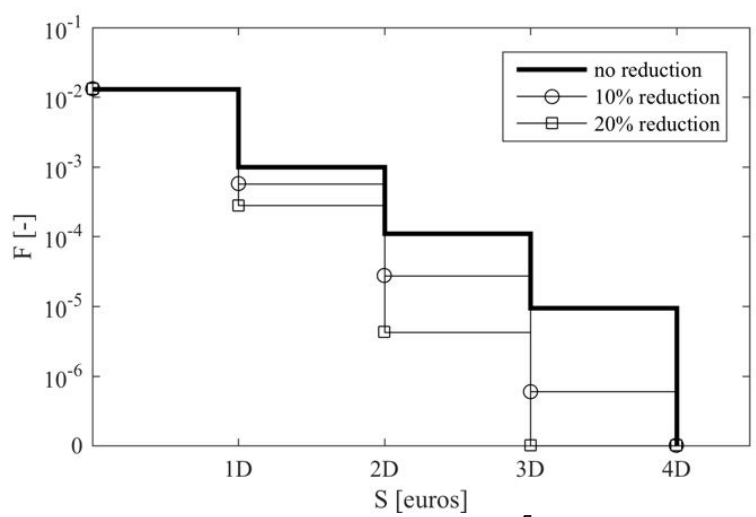

Figure 7. Flood loss $(S)$ curves with $10^{7}$ samples for the system in Figure 3A. Exceedance probabilities $(F)$ are shown for no impact and positive impact ( $10 \%$ and $20 \%$ discharge reduction), using equal damages $D$ per defence.

\begin{tabular}{lcccc}
\hline & Defence & Defence & Defence & Defence \\
& 1 & 2 & 3 & 4 \\
\hline$C_{f}[€]$ & $20 \cdot 10^{6}$ & $20 \cdot 10^{6}$ & $20 \cdot 10^{6}$ & $20 \cdot 10^{6}$ \\
\hline$C_{v}[€ / \mathrm{m}]$ & $10 \cdot 10^{6}$ & $10 \cdot 10^{6}$ & $10 \cdot 10^{6}$ & $10 \cdot 10^{6}$ \\
\hline$r[-]$ & 0.04 & 0.04 & 0.04 & 0.04 \\
\hline
\end{tabular}

Table 3. Economic values for the defences in Figure 3. 


\subsection{Calculations and results}

Each of the three systems shown in Figure 3 will initially be calculated with three configurations of potential flood damages. These configurations will be the same for each system, and are shown in Table 4. The number of samples during each Monte Carlo run is $10^{7}$.

\begin{tabular}{lcccc}
\hline & $D_{1}$ & $D_{2}$ & $D_{3}$ & $D_{4}$ \\
\hline Config. 1 & $10^{8}$ & $10^{8}$ & $10^{8}$ & $10^{8}$ \\
\hline Config. 2 & $5 \cdot 10^{7}$ & $5 \cdot 10^{7}$ & $5 \cdot 10^{7}$ & $5 \cdot 10^{7}$ \\
\hline Config. 3 & $10^{7}$ & $10^{7}$ & $10^{7}$ & $10^{8}$ \\
\hline
\end{tabular}

Table 4. Configurations used for the systems of Figure 3.

The calculation results, with and without impacts, for Figure 3A, Figure 3B and Figure 3C are shown in Table 5 , Table 6 and Table 7, respectively. Calculation results with impacts that are different from the results without impacts are marked bold. The first thing that stands out is that configuration 1 and configuration 2 of Table 4 do not lead to different optimal values when including impacts. Only in the case of configuration 3, where flood defence 4 has a significantly higher potential flood damage when compared to the other flood defences, we see different results.

First, for the system with positive interaction in Table 5 the optimal heights for configuration 3 with impacts are a step lower than without impacts for most of the defences. The calculation with impacts has been repeated a few times, and lead to some interesting results. The number of defences with lower optimal heights differs between runs, and ranges between two to four. Apparently, small variations in the Monte Carlo estimation of the failure probability lead to these changes. This indicates that the total cost difference between some of these combinations is small.

Secondly, the system with predominantly negative impacts for configuration 3 in Table 6 shows an increase in height for flood defence 3 , and a large increase in height for flood defence 4 . When looking at the failure probabilities of defence 4 with and without impact, the optimal height of defence 4 would probably need to be even higher. Regarding the first three defences, which defence (and how many) should be a step higher tends to differ when the calculations are repeated. Again, this can probably be attributed to small total cost differences between the various system configurations.

Thirdly, the system with mixed impacts for configuration 3 in Table 7 indicates that the first and third flood defence should be increased with a single step, while the second defence should be decreased with a single step. Repeated runs did not lead to different configurations, but given the results with the other two systems, the difference in total costs might still be small.

Finally, the optimal failure probabilities show some interesting results as well. Generally speaking, the optimal failure probabilities with and without impact seem to be similar. Even when the optimal height of defences with impacts tends to differ from the optimal height without impact, the failure probabilities are approximately similar. Any differences in failure probabilities can be attributed to the limited number of steps, and the step size of 0.2 meter.

\begin{tabular}{cccccc}
\hline Configuration 1 & & Defence 1 & Defence 2 & Defence 3 & Defence 4 \\
\cline { 2 - 6 } & & $D_{1}=10^{8}$ & $D_{2}=10^{8}$ & $D_{3}=10^{8}$ & $D_{4}=10^{8}$ \\
\hline $\begin{array}{c}\text { Optimal values } \\
\text { (no impacts) }\end{array}$ & $h[\mathrm{~m}]$ & 8.18 & 8.18 & 8.18 & 8.18 \\
\cline { 2 - 6 } & $P[-]$ & $1 / 368$ & $1 / 368$ & $1 / 368$ & $1 / 368$ \\
\hline $\begin{array}{c}\text { Optimal values } \\
\text { (with impacts) }\end{array}$ & $h[\mathrm{~m}]$ & 8.18 & 8.18 & 8.18 & 8.18 \\
\cline { 2 - 6 } & $P[-]$ & $1 / 369$ & $1 / 375$ & $1 / 387$ & $1 / 389$ \\
\hline
\end{tabular}

\begin{tabular}{|c|c|c|c|c|c|}
\hline \multirow{2}{*}{ Configuration 2} & & Defence 1 & Defence 2 & Defence 3 & Defence 4 \\
\hline & & $D_{1}=5 \cdot 10^{7}$ & $D_{2}=5 \cdot 10^{7}$ & $D_{3}=5 \cdot 10^{7}$ & $D_{4}=5 \cdot 10^{7}$ \\
\hline \multirow{2}{*}{$\begin{array}{l}\text { Optimal values } \\
\text { (no impacts) }\end{array}$} & $h[\mathrm{~m}]$ & 7.70 & 7.70 & 7.70 & 7.70 \\
\hline & $P[-]$ & $1 / 182$ & $1 / 182$ & $1 / 182$ & $1 / 182$ \\
\hline \multirow{2}{*}{$\begin{array}{l}\text { Optimal values } \\
\text { (with impacts) }\end{array}$} & $h[\mathrm{~m}]$ & 7.70 & 7.70 & 7.70 & 7.70 \\
\hline & $P[-]$ & $1 / 182$ & $1 / 189$ & $1 / 193$ & $1 / 199$ \\
\hline \multirow{2}{*}{ Configuration 3} & & Defence 1 & Defence 2 & Defence 3 & Defence 4 \\
\hline & & $D_{1}=10^{7}$ & $D_{2}=10^{7}$ & $D_{3}=10^{7}$ & $D_{4}=10^{8}$ \\
\hline \multirow{2}{*}{$\begin{array}{l}\text { Optimal values } \\
\text { (no impacts) }\end{array}$} & $h[\mathrm{~m}]$ & 6.55 & 6.55 & 6.55 & 8.18 \\
\hline & $P[-]$ & $1 / 35$ & $1 / 35$ & $1 / 35$ & $1 / 368$ \\
\hline \multirow{2}{*}{$\begin{array}{l}\text { Optimal values } \\
\text { (with impacts) }\end{array}$} & $h[\mathrm{~m}]$ & 6.35 & 6.35 & 6.55 & 7.98 \\
\hline & $P[-]$ & $1 / 27$ & $1 / 28$ & $1 / 40$ & $1 / 391$ \\
\hline
\end{tabular}

Table 5. Results with and without impacts for the system in Figure 3A. 


\begin{tabular}{|c|c|c|c|c|c|}
\hline \multirow{2}{*}{ Configuration 1} & & Defence 1 & Defence 2 & Defence 3 & Defence 4 \\
\hline & & $D_{l}=10^{8}$ & $D_{2}=10^{8}$ & $D_{3}=10^{8}$ & $D_{4}=10^{8}$ \\
\hline \multirow{2}{*}{$\begin{array}{l}\text { Optimal values } \\
\text { (no impacts) }\end{array}$} & $h[\mathrm{~m}]$ & 8.16 & 8.16 & 8.16 & 8.18 \\
\hline & $P[-]$ & $1 / 365$ & $1 / 365$ & $1 / 365$ & $1 / 368$ \\
\hline \multirow{2}{*}{$\begin{array}{l}\text { Optimal values } \\
\text { (with impacts) }\end{array}$} & $h[\mathrm{~m}]$ & 8.16 & 8.16 & 8.16 & 8.18 \\
\hline & $P[-]$ & $1 / 360$ & $1 / 364$ & $1 / 375$ & $1 / 311$ \\
\hline \multirow{2}{*}{ Configuration 2} & & Defence 1 & Defence 2 & Defence 3 & Defence 4 \\
\hline & & $D_{1}=5 \cdot 10^{7}$ & $D_{2}=5 \cdot 10^{7}$ & $D_{3}=5 \cdot 10^{7}$ & $D_{4}=5 \cdot 10^{7}$ \\
\hline \multirow{2}{*}{$\begin{array}{l}\text { Optimal values } \\
\text { (no impacts) }\end{array}$} & $h[\mathrm{~m}]$ & 7.69 & 7.69 & 7.69 & 7.70 \\
\hline & $P[-]$ & $1 / 183$ & $1 / 183$ & $1 / 183$ & $1 / 182$ \\
\hline \multirow{2}{*}{$\begin{array}{l}\text { Optimal values } \\
\text { (with impacts) }\end{array}$} & $h[\mathrm{~m}]$ & 7.69 & 7.69 & 7.69 & 7.70 \\
\hline & $P[-]$ & $1 / 179$ & $1 / 185$ & $1 / 190$ & $1 / 148$ \\
\hline \multirow{2}{*}{ Configuration 3} & & Defence 1 & Defence 2 & Defence 3 & Defence 4 \\
\hline & & $D_{1}=10^{7}$ & $D_{2}=10^{7}$ & $D_{3}=10^{7}$ & $D_{4}=10^{8}$ \\
\hline \multirow{2}{*}{$\begin{array}{l}\text { Optimal values } \\
\text { (no impacts) }\end{array}$} & $h[\mathrm{~m}]$ & 6.53 & 6.53 & 6.53 & 8.18 \\
\hline & $P[-]$ & $1 / 35$ & $1 / 35$ & $1 / 35$ & $1 / 368$ \\
\hline \multirow{2}{*}{$\begin{array}{l}\text { Optimal values } \\
\text { (with impacts) }\end{array}$} & $h[\mathrm{~m}]$ & 6.53 & 6.53 & 6.73 & 8.58 \\
\hline & $P[-]$ & $1 / 34$ & $1 / 36$ & $1 / 51$ & $1 / 276$ \\
\hline
\end{tabular}

Table 6. Results with and without impacts for the system in Figure 3B.

\begin{tabular}{|c|c|c|c|c|c|}
\hline \multirow{2}{*}{ Configuration 1} & & Defence 1 & Defence 2 & Defence 3 & Defence 4 \\
\hline & & $D_{1}=10^{8}$ & $D_{2}=10^{8}$ & $D_{3}=10^{8}$ & $D_{4}=10^{8}$ \\
\hline \multirow{2}{*}{$\begin{array}{l}\text { Optimal values } \\
\text { (no impacts) }\end{array}$} & $h[\mathrm{~m}]$ & 8.16 & 8.18 & 8.16 & 8.18 \\
\hline & $P[-]$ & $1 / 365$ & $1 / 368$ & $1 / 365$ & $1 / 368$ \\
\hline \multirow{2}{*}{$\begin{array}{l}\text { Optimal values } \\
\text { (with impacts) }\end{array}$} & $h[\mathrm{~m}]$ & 8.16 & 8.18 & 8.16 & 8.18 \\
\hline & $P[-]$ & $1 / 361$ & $1 / 349$ & $1 / 363$ & $1 / 357$ \\
\hline \multirow[b]{2}{*}{ Configuration 2} & & Defence 1 & Defence 2 & Defence 3 & Defence 4 \\
\hline & & $D_{1}=5 \cdot 10^{7}$ & $D_{2}=5 \cdot 10^{7}$ & $D_{3}=5 \cdot 10^{7}$ & $D_{4}=5 \cdot 10^{7}$ \\
\hline \multirow{2}{*}{$\begin{array}{l}\text { Optimal values } \\
\text { (no impacts) }\end{array}$} & $h[\mathrm{~m}]$ & 7.69 & 7.70 & 7.69 & 7.70 \\
\hline & $P[-]$ & $1 / 183$ & $1 / 182$ & $1 / 183$ & $1 / 182$ \\
\hline \multirow{2}{*}{$\begin{array}{l}\text { Optimal values } \\
\text { (with impacts) }\end{array}$} & $h[\mathrm{~m}]$ & 7.69 & 7.70 & 7.69 & 7.70 \\
\hline & $P[-]$ & $1 / 179$ & $1 / 171$ & $1 / 184$ & $1 / 177$ \\
\hline \multirow{2}{*}{ Configuration 3} & & Defence 1 & Defence 2 & Defence 3 & Defence 4 \\
\hline & & $D_{1}=10^{7}$ & $D_{2}=10^{7}$ & $D_{3}=10^{7}$ & $D_{4}=10^{8}$ \\
\hline \multirow{2}{*}{$\begin{array}{l}\text { Optimal values } \\
\text { (no impacts) }\end{array}$} & $h[\mathrm{~m}]$ & 6.53 & 6.55 & 6.53 & 8.18 \\
\hline & $P[-]$ & $1 / 35$ & $1 / 35$ & $1 / 35$ & $1 / 368$ \\
\hline \multirow{2}{*}{$\begin{array}{l}\text { Optimal values } \\
\text { (with impacts) }\end{array}$} & $h[\mathrm{~m}]$ & 6.73 & 6.35 & 6.73 & 8.18 \\
\hline & $P[-]$ & $1 / 45$ & $1 / 25$ & $1 / 47$ & $1 / 358$ \\
\hline
\end{tabular}

Table 7. Results with and without impacts for the system in Figure 3C. 


\section{Sensitivity discharge fraction}

The discharge fraction which flows into a polder area due to breaching was set to ten percent in the previous section. As this discharge fraction is the primary driver behind any differences obtained in Section 5 with respect to optimal values with and without impacts, it makes sense to see what happens if this fraction is altered. Any significant differences in optimal values encountered in Section 5 were limited to some specific system configurations. Therefore, all the systems and configurations of Section 5 were re-run with an increased discharge fraction set at twenty percent.

First, for the system with positive impacts in Figure $3 \mathrm{~A}$ the results with an increased discharge fraction were similar to those found in Table 5. The only result that changed was that for configuration 3 , the third flood defence height is lowered with a single step as well.

Secondly, for the system with negative impacts in Figure $3 \mathrm{~B}$ the change in discharge fractions is noticeable, as configuration 2 now showed a difference as well: flood defence four gets a height increase with a single step. Furthermore, configuration 3 with an increased discharge fraction showed a greater difference than with a discharge fraction of ten percent; the height of the first three flood defences increased with a single step, and the height of the fourth flood defence increased with two steps.

Thirdly the system with mixed impacts in Figure 3C showed, similar to the system with negative impacts, a significant difference in optimal system states was found. Configuration 1 sees flood defence 1 increased with a single step, configuration has the first and third flood defence increased with a single step, while configuration 3 has the first, third and fourth flood defence increased with a single step, while the second flood defence gets decreased with a single step.

The system with mixed impacts and an increased discharge fraction also showed differences regarding the optimal failure probabilities, especially for configuration 2, which can no longer be attributed solely to the step size of 0.2 meter. The optimal failure probabilities are shown in Table 8 .

\begin{tabular}{ccccc}
\hline & Defence 1 & Defence 2 & Defence 3 & $\begin{array}{l}\text { Defence } \\
4\end{array}$ \\
\hline C1 & $1 / 478$ & $1 / 331$ & $1 / 367$ & $1 / 321$ \\
\hline C2 & $1 / 241$ & $1 / 161$ & $1 / 252$ & $1 / 163$ \\
\hline C3 & $1 / 45$ & $1 / 23$ & $1 / 49$ & $1 / 323$ \\
\hline
\end{tabular}

Table 8. Optimal failure probabilities using a $20 \%$ discharge fraction for the three configurations $(\mathrm{C} 1, \mathrm{C} 2, \mathrm{C} 3$, see also Table 4) of the system with mixed impacts (Figure 3C).

The decreased optimal failure probabilities for defence 1 and 3 for configuration 2 in Table 8 can be attributed to the used discharge distribution over River $\mathrm{A}$ $(2 / 3 Q)$ and River $\mathrm{B}(1 / 3 Q)$. Because shortcutting in the systems of Figure 3 can only happen from River $A$ to river $\mathrm{B}$, a twenty percent discharge reduction from River A effectively leads to a forty percent discharge increase in River B. Keeping in mind that the investment costs are equal among all flood defences, it becomes relatively cheap to invest extra in the defences that are prone to shortcutting. This agrees with results found in earlier work on coastal flood defence systems $([5,6])$, which indicated that for a system with a front defence (similar to a flood defence prone to shortcutting), extra investments in this front defence become economically attractive once it is either cheaper to upgrade and/or more effective at reducing risk (compared to the downstream defences).

Even though the discharge fraction was increased to twenty percent, results from repeated runs still showed small variations with respect to the optimal system configuration. As mentioned in Section 5, this can probably be attributed to small variations in the Monte Carlo failure probability estimations, which also means that differences in total costs will probably be small. One of these runs showing this behavior is the system with mixed impacts in configuration 1 . In order to further examine these changes, the risk costs, investment costs and total costs of the system with mixed impacts in configuration 1 are shown in Table 9.

Table 9 shows that the difference in total costs (risk costs plus investment) for a given discharge fraction is less than one percent of the risk costs for both discharge fractions. As the difference in estimated failure probabilities between Monte Carlo runs can be in the order of one percent with the used number of samples, this seems to be a valid explanation for the optimal height differences between different runs.

\begin{tabular}{lcc}
\hline & $\begin{array}{c}\text { Risk Costs } \\
\text { [euro] }\end{array}$ & $\begin{array}{c}\text { Investment } \\
\text { [euro] }\end{array}$ \\
\hline $\begin{array}{l}\text { 'No impact' heights, } \\
Q_{\text {red }}=10 \%\end{array}$ & $2.8171 \cdot 10^{7}$ & $40.68 \cdot 10^{7}$ \\
\hline $\begin{array}{l}\text { Defence } 1+0.2 \mathrm{~m}, \\
Q_{\text {red }}=10 \%\end{array}$ & $2.6100 \cdot 10^{7}$ & $40.88 \cdot 10^{7}$ \\
\hline $\begin{array}{l}\text { 'No impact' heights, } \\
Q_{\text {red }}=20 \%\end{array}$ & $2.9700 \cdot 10^{7}$ & $40.68 \cdot 10^{7}$ \\
\hline $\begin{array}{l}\text { Defence } 1+0.2 \mathrm{~m}, \\
Q_{\text {red }}=20 \%\end{array}$ & $2.7447 \cdot 10^{7}$ & $40.88 \cdot 10^{7}$ \\
\hline
\end{tabular}

Table 9. Cost comparison for the system with mixed impacts in configuration 1 , for both discharge fractions $\left(Q_{\text {red }}\right)$.

\section{Conclusion}

The results in Sections 5 and 6 show that the effect of positive impacts on both the optimal failure probability and the optimal heights seem to be limited to cases that meet some specific requirements, with different results regarding the optimal failure probabilities and optimal flood defence heights. Regarding the optimal failure probabilities, significant differences between using impacts and not using them were, in this paper, limited to flood defences prone to shortcutting in the system with mixed interaction using a twenty percent discharge fraction in configuration 2 (Table 8 ). Therefore, the effect on the target failure probabilities (safety standards) seems to be limited in small systems and only noticeable in 
systems such as the aforementioned system. The effects may be larger when systems with more potential breach locations and areas are considered, such as for example the Lower Rhine River (e.g. [21]).

However, regarding the optimal defence heights, a broader set of changes was detected, compared to the optimal heights calculated without impacts. Nevertheless, the effect of positive impacts seems to be limited when compared to negative impacts, which can also be seen in the results belonging to the mixed impacts system.

In general, the results from this study indicate that there can be a significant effect of breach impacts if one or more of the following system characteristics apply:

- Relatively large failure probabilities

- Relatively large differences in potential flood damage between flood defences

- Relatively large impact of a breach on the river discharge(s)

Furthermore, the chosen step size of 0.2 meter in defence height proved to be too small, at least from the perspective of the uncertainties regarding the failure probability estimation. This was noticed because repeated optimisation runs lead to small differences in the optimal flood defence heights. In practice, these uncertainties exist as well, which might warrant larger step sizes in order to obtain reproducible, significantly different result. Nevertheless, if a practical case study meets one or more of the aforementioned requirements, indications have been found in this study that in principle a different costoptimal investment path can be found when including impacts.

\section{Acknowledgements}

We are grateful for the financial support of the Dutch Technology Foundation STW, which is part of the Netherlands Organization for Scientific Research, which is partly funded by the Ministry of Economic Affairs.

\section{References}

1. Kind J.M. (2014). Economically efficient flood protection standards for the Netherlands. Journal of Flood Risk Management, 7, 103-117.

2. Custer R. (2015). Hierarchical Modelling of Flood Risk for Engineering Decision Analysis Technical University of Denmark.

3. Tsimopoulou V. (2015). Economic optimisation of flood risk management projects Delft University of Technology.

4. Zwaneveld P. and Verweij G. (2014). Economisch optimale waterveiligheid in het IJsselmeergebied. The Hague.

5. Dupuits E.J.C. and Schweckendiek T. (2015). Flood risk and economically optimal safety targets for coastal flood defense systems. In: Haukaas T, editor. ICASP12: 12th International Conference on Applications of Statistics and Probability in Civil Engineering, Vancouver, Canada, 12-15 July 2015. Vancouver.

6. Dupuits E.J.C., Schweckendiek T., and Kok M.
(2016). [In preparation] Economic Optimization of Coastal Flood Defence Systems. Reliability Engineering \& System Safety,.

7. Vorogushyn S., Merz B., Lindenschmidt K.-E., and Apel H. (2010). A new methodology for flood hazard assessment considering dike breaches. Water Resources Research, 46.

8. Vorogushyn S., Lindenschmidt K.-E., Kreibich H., Apel H., and Merz B. (2012). Analysis of a detention basin impact on dike failure probabilities and flood risk for a channel-dike-floodplain system along the river Elbe, Germany. Journal of Hydrology, 436-437, 120-131.

9. Courage W., Vrouwenvelder T., van Mierlo T., and Schweckendiek T. (2013). System behaviour in flood risk calculations. Georisk: Assessment and Management of Risk for Engineered Systems and Geohazards, 7, 62-76.

10. De Bruijn K.M., Diermanse F.L.M., and Beckers J.V.L. (2014). An advanced method for flood risk analysis in river deltas, applied to societal flood fatality risks in the Netherlands. Natural Hazards and Earth System Sciences Discussions, 1637-1670.

11. Van der Wiel W.D. (2004). Probabilistic risk assessment of a system of dike ring areas Delft University of Technology.

12. Klerk W.J. (2013). Load interdependencies of flood defences Delft University of Technology.

13. Jongejan R., Maaskant B., ter Horst W., Havinga F., Roode N., and Stefess H. (2013). The VNK2-project: a fully probabilistic risk analysis for all major levee systems in the Netherlands. Floods: From Risk to Opportunity (IAHS Publ. 357). IAHS Press, Vol. 2005. pp. 75-85.

14. Vrijling J.K. (2013). Multi layer safety. Safety, Reliability and Risk Analysis. CRC Press. pp. 37-43.

15. Vrijling J.K. and van Beurden I.J.C.A. (1990), Sealevel rise: a probabilistic design problem. Coastal Engineering Proceedings, 1160-1171.

16. Eijgenraam C.J.J. (2006). Optimal safety standards for dike-ring areas. The Hague.

17. Van Dantzig D. (1956). Economic Decision Problems for Flood Prevention. Econometrica, 24, 276-287.

18. Diermanse F.L.M., Bruijn K.M., Beckers J.V.L., and Kramer N.L. (2014). Importance sampling for efficient modelling of hydraulic loads in the Rhine-Meuse delta. Stochastic Environmental Research and Risk Assessment, 29, 637-652.

19. Kanning W., van Baars S., van Gelder P., and Vrijling J. (2007). Lessons from New Orleans for the design and maintenance of flood defence systems. In: Aven, and Vinnem, editors. Proceedings of the European safety and reliability conference 2007 (ESREL 2007). London: Taylor \& Francis Group. pp. 937-942.

20. Zwaneveld P.J. and Verweij G. (2014). Safe Dike Heights at Minimal Costs. The Hague. 40 p.

21. De Bruijn K.M., Diermanse F.L.M., Van der Doef M., and Klijn K. (2016). Hydrodynamic system behaviour: its analysis and implications for flood risk management. FloodRisk2016 conference. Lyon. 